\title{
Analysis of recombination rate in female and male gametogenesis in pearl millet (Pennisetum glaucum) using RFLP markers
}

Received: 9 May 1994 / Accepted: 8 September 1994

\begin{abstract}
Sex as a factor affecting recovered recoinbination in plant gametes was investigated in pearl millet. Pennisetum glaucum, by using reciprocal three-way crosses $[(\mathrm{A} \times \mathrm{B}) \times \mathrm{C} \vee \mathrm{C} \times(\mathrm{A} \times \mathrm{B})]$. The two populations were mapped at 42 loci pre-selected to cover the majority of the genome. No differences in recombination distances were observed at the wholc-genomi level and only a few individual linkage intervals were found to differ, all in favour of increased recombination through the male. Distorted segregations found in the threc-way crosses provide evidence of post-gametic selection for particular gene(s) or chromosome regions. The significance of these results for the design of pcarl millet breeding programmes and inheritance experiments, as well as for other experimental strategies, is discussed.
\end{abstract}

Key words Pennisetum glaucum - RFLP analysis Recombination rate Segregation distortion Genetic mechanisms

\section{Introduction}

Recombination at meiosis and the factors that influence recombination rates have been studied extensively. One such factor is the relative recombination rates recovered in male and female gametes. In animals such as Drosophila (Baker et al. 1976) and humans (Donis-Keller et al. 1987) the evidence shows that recombination is much higher in the female. However, analysis of recombination frequencies in mouse (Reeves 1990) and silk worm (Maeda 1939)

Communicated by P. L. Pfahler

C. S. Busso - C. J. Liu - K. M. Devos · M. D. Gale (四)

Cambridge Laboratory, Colney, Norwich, NR4 7UJ, UK

C. T. Hash . J. M. J. de Wet

International Crops Research Institute for the Semi-Arid Tropics

(ICRISAT), Patancheru PO 502 324, Andhra Pradesh, India

J. R. Witcombe

Centre for Arid Zone Studies, University of Wales, Bangor

Gwynedd LL57 2UW, UK demonstrated higher values in male gametes. In plants, where a clear effect of sex on recombination could be ex. ploited in breeding programmes, the evidence is also equivocal. A number of studies. e.g.. in Zea rlu, is (Robertson 1984) and Arabidopsis thaliama (Zhuchenko et al. 1989). have shown a tendency towards increased recombination in the male. However, these results do not exclude the possibility that the differences are restricted (1) particular chromosome regions since all the studies involved a limited number of recombination intervals using available morphological or protcin marker loci.

With the development of DNA markers and the construction of extensive genetic maps, analyses of recombination frequencies can be extended to an entire genome. In a comparison of male versus female recombination in two backcross populations of tomato using RFLP markers, De Vicente and Tanksley (1991) reported a significantly higher recombination rate in female meiosis. This result was associated with a skewed allelic segregation, as has been observed in many of the molecular mapping projects in plant crop species, e.g., in barley (Heun et al. 1991) and in pearl millet (Liu et al. 1994). These reports indicated that the skewed segregation could not explain the differences in recombination rates. It is clearly important to establish whether the direction and extent of the sex differences in recombination rates in tomato reflect a general situation in plants. From a practical standpoint both differential recombination in inale and female.meiosis and distorted segregation, if predictable, can be exploited to the plant breeders' advantage.

In this paper we report the results of experiments in pearl millet, Pennisetum glaucum, designed to examine the effects of sex on recombination and segregation distortion with a view to possible exploitation in breeding strategies.

\section{Materials and methods}

\section{Genetic material}

Three genotypes, each of which had been inbred for more than nine generations, were used in three-way crosses: 81B (a downy mildew- 
resistant selection from gamma-irradiated Tift 23DB). ICMP 4.51 (derived from L.CSN 72-1-2-1-1. a selection made in Upper Volta from the ICRISAT Center Late Composite) and BKM 1163 (an inbred derived from crosses between Tift 23DB and a Ghanaian landrace).

F, plants of $81 \mathrm{~B} \times 1 \mathrm{CMP} 451$ were obtained by protogyny-facilitated hand pollination without employing emasculation. A single typical $F_{1}$ plant was then crossed as both male and female with the third parent. BKM 1163. All pollinations were carried out at $35 \mathrm{C}$ in a glasshouse with natural daylength at the ICRISAT Center, and were repeated on 3 consecutive days 10 reduce the probability of selfing.

The parents were morphologically distinct: $81 \mathrm{~B}$ is dwarf and has hairy leaf blades: ICMP 451 is tall, with bristled panicles and smooth leaf blades: and BKM 1163 is dwarf, with smooth leaf blades and amber seed colour. $F_{1}$ plants of $81 B \times$ ICMP 451 were distinguished from selfs by the dominant characteristics of the male parent (smooth leaf blades, bristled panicles. and tall plants). $F_{1}$ seed of the threeway cross having BKM 1163 as the male parent. TWC 8 . $\mid(81 B \times$ ICMP 451) $\times$ BKM 116.31 were distinguished from selfed seed by $x e n i a$ for amber coloured endosperm colour, whereas selfed and $F_{1}$ seed in TWC? [BKM $116.3 \times(81 \mathrm{~B} \times$ ICMP 4.51$)$ ) were indistinguishable.

From each three-way cross, TWC $\&$ and TWC o, 112 plants were grown (o) the five-leaf stage and then harvested direcily into liquid nitrogen before frecze drying. This material, logether with leaf samples from the parental and $F_{1}$ genotypes, was further characterized at the Cambridge Laboratory.

\section{RFLP analysis}

Sixty-eight low-copy PSM DNA clones were chosen to provido coverage of the current pearl millet map (Liu et al. 1994). Of these 41 were found to be informative and were used for mapping the threeway crosses. Analyses with the restriction enzymes E(o) RI, E(oRV. Dral and HindIII were carricd out as described by Liu et al. (1994). The segregation data were analyzed using Mapmaker v1.9. Whitehead Institute, Mass., USA (Lander et al. 1987). The maps are presented in $\mathrm{cM}$, using the Haldane mapping function.

\section{Results}

The use of three-way crosses allowed off-type progenies, in particular those produced by selfing, to be identified unequivocally (Fig. 1). After elimination of such progenies, the segregation data for the 112 TWC $\&$ plants and the remaining 107 TWC \& plants were analyzed to produce two genetic maps (Fig. 2). In all cases the marker order and linkage group assignment. of the $\$ 2$ loci that could be mapped using the 41 probes, was consistent between the reciprocial crosses and the map constructed in an independent $F_{2}$ (LGD-I-B-10) ICMP 8.5410) population by Liu et al. (1994).

\section{Recombination in male and female gametes}

The total map distances estimated in the two populations did not differ significiantly, being $2.34 \mathrm{cM}$ in TWC 9 and $267 \mathrm{cM}$ in TWC $d$. These values were also similar to the $255.3 \mathrm{cM}$ map distance spanned by the same markers in the (L.GD-1-B-10) ICMP 85410) F, map.

Analysis of the seven linkage groups showed that in only one, the short linkage group 3. Was there a difference $(P<0.05)$ between the length of the TWC $\delta$ map (22 cM) and the length of the TWC $q$ map $(9 \mathrm{cM})$. However, observation of the remaining six groups shows clearly that the sex difference does not reflect a general trend. The analysis of the 3.5 linkage intervals for which reciprocal data were available showed that only three intervals were significantly different at $P<0.05$, and of these only two were significantly different at $P<(0.01$. These were $X p$ sim22.3$X p s m 607$ in linkage group $1, \chi_{(1)}^{2}=7.4$, and $X p . m 45 / B$ $X p s m 248$ in linkage group $3, \chi_{(1)}^{2}=7.1$, with the TWC o map having the larger value in each case.

\section{Segregation distortion}

The three-way cross design allowed transmission of the alternative $81 \mathrm{I}$ and ICMP 45I alleles through pollen and egg cells to be scored with precision. Severe distortion from the expected 1:1 ratio was observed, only in TWC of, for alleles at loci in linkage groups 1,4 and 7 . The 12 loci sig-
Fig. 1 Segregation of $X$ psm 466 in parents $(A, B)$, the $F_{1}$ plant and a sample of the TWC ơ $[\mathrm{C} \times(\mathrm{A} \times \mathrm{B})]$ population digested with Dral. Note, the individual progenies are classified by parental genotypc $(A$ or $B)$, always recovered with the female $C$ allele, and offtype (homozygous $C$ ) in the case of two selfed progeny

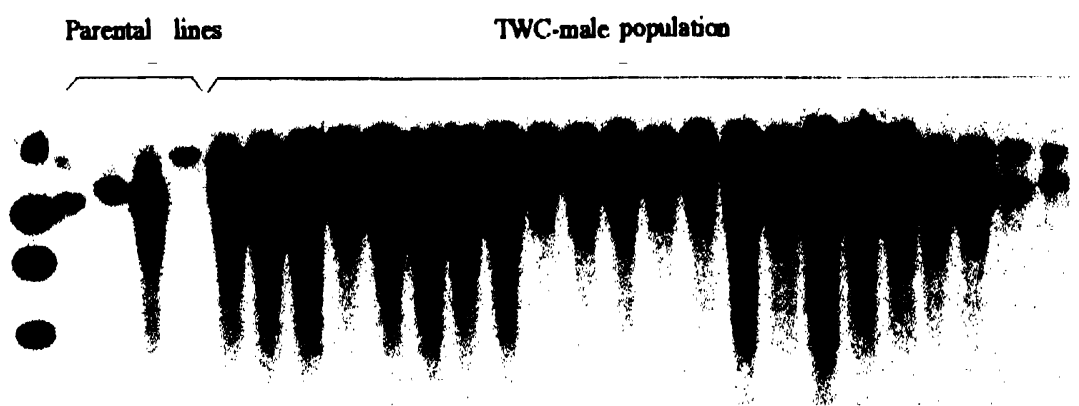

A B F1CB B B B A B B A C B B B B CABAABAB 
UNKAGE GROUP 1

(720) TwC- (103.2) TWC $\delta$

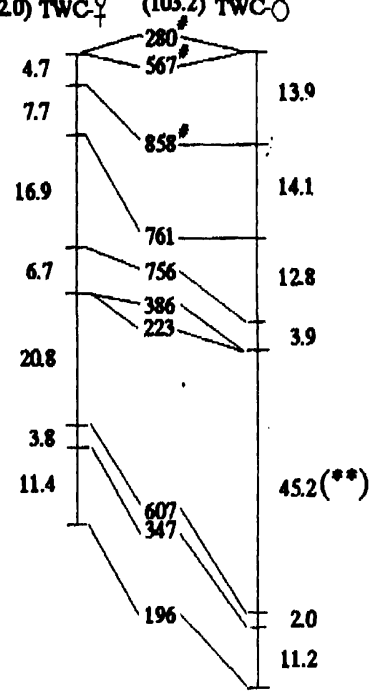

UNKAGE GROUP 5
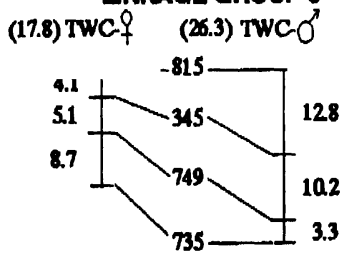

UNKAGE GROUP 2

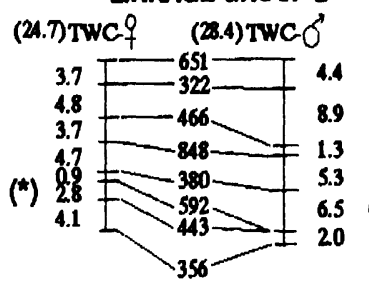

LNKAGE GROUP 3

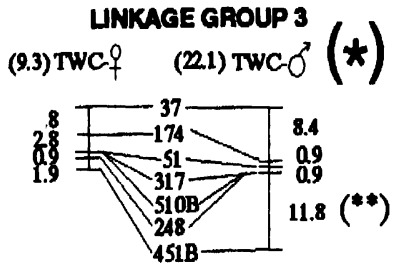

LNKAGE GROUP 6

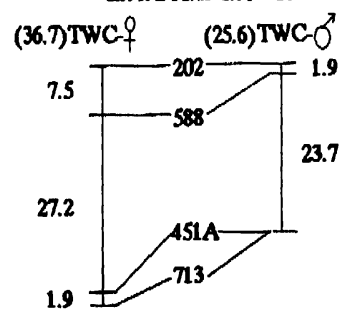

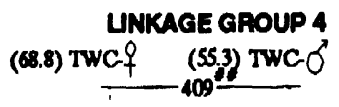

15.5

16.5

(\$)

38.8

29.8

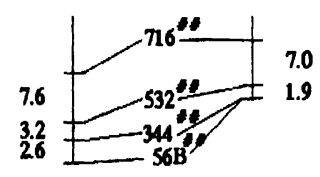

LNKAGE GROUP 7

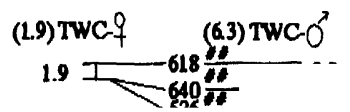

Fig. 2 Male and female genetic maps. Note, linkage groups or intervals showing differences between the TWC $\delta$ and TWC $\$$ map are shown by $* P<0.5$ and $* * P<0.01$ in the direction of greater recombination. Loci showing distorted segregation, found only in the TWC o s population, are shown by $\# P<0.05$ and $\# \# P<0.01$

nificantly affected in TWC $\delta$ all showed segregation in favour of the ICMP 45 I alleles (Fig. 3) and smaller non-significant biases occurred in TWC $q$ along part of linkage group 1 and most of linkage group 4 (Fig. 3).

\section{Discussion}

Analysis of the 81B $\times$ ICMP 451 three-way crosses confirms the findings of Liu et al (1994) in that the markers mapped in the expected linear arrangement on the same chromosomes, separated by linkage distances similar to those previously observed. Thus the analyses also confirmed the extremely short genetic map described by Liu et al. using 181 random markers. Although the map has not been capped by mapped telomeres it is unreasonable to expect that, with an average of 26 markers per chromosome, a large portion of the genome lies outside the distal markers. Genetic lengths of between 100 and $200 \mathrm{cM}$ per chromosome appear to be the norm in other cereals, e.g., bar- ley (Kleinhofs et al. 1993) and wheat (Devos et al. 1993). It is probable therefore that the low level of recombination per chromosome will limit the rate of progress achieved by pearl millet breeders. Thus any means of maximising recombination will be of value. For example, more generations of random mating can be made, before selection commences, in the creation of composite populations. Also, in population improvement by recurrent selection, mass selection and full-sib progeny selection, which allow frequent recombination generations, can be used rather than methods which predominantly use selfing generations. However, an advantage of the genetically short chromosomes is that they provide an excellent test bed for experiments, such as the one reported here, to measure the effects of factors that influence recombination. Moreover, marker-assisted recovery of non-target recurrent parent chromosomes in backcross breeding programmes will be easy, and relatively inexpensive, in this species.

\section{Differences in male and female recombination}

The experiments described here were designed to eliminate other factors that could affect recombination rates in plants. Temperature and photoperiod at meiosis were controlled. Individual genotype effects were eliminated by the use of a single $F_{1}$ plant as both male and female in the backcrosses. The effects of non-collinearity, as might be found 
UNKAGE

GROUP 1

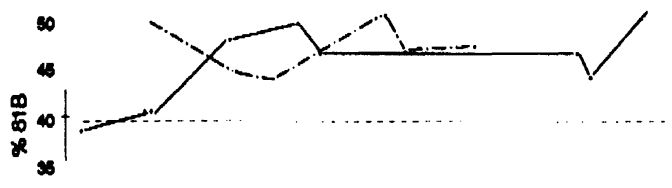

$\infty$

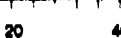

$\infty \infty \infty$

$\infty$

$100 \mathrm{CM}$

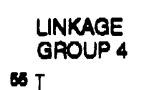

$\infty$

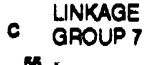

65 $\prod_{\infty}^{\infty} 4$
20

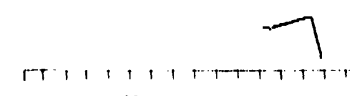

0

20

40

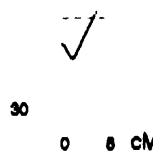

-. $\mathrm{CN}$

Fig. 3 Disturbance in the ratio of alleles recovered in TWC $\delta$. Note, for the three regions of the genome affected TWC $?$ is shown as $(-.-$.$) and TWC \delta$ as (-) against the expected $50 \%$ allelic re. covery rate $(\ldots . . . .$.$) and the 95 \%$ confidence limit $(-. . .$.

in interspecific crosses, were minimised by using adapted P. glaucum inbreds, and this was eventually confirmed by the maps themselves. Any cytoplasmic effect or cytoplasmic-nuclear interaction effect was avoided since both females in the three-way crosses had Tift 23DB cytoplasm. Moreover, the use of three-way crosses allowed the unequivocal identification of off-type progeny (Fig. 1), particularly those that might arise by selfing, as is quite possible with the hand pollination methods used to produce large amounts of hybrid seed per panicle in pearl millet. However, one effect could not be controlled. Strong selection for or against specific alleles in various regions of the genome, through either the male or female gametes, could decrease measured recombination values. This possibility is discussed further below.

The TWC $\delta$ and TWC $q$ maps indicate clearly that the differences in recovered male and female recombination rates are minimal. Results recently obtained in this laboratory (Liu and Gale, unpublished) indicate that the lack of large differences in male and female recombination rates extends to interspecific crosses in Pennisetum.

\section{Distorted segregations}

Selection for coupling linkages would result in reduction in recombination. Such selection would be reflected in segregation of markers distorted from the expected 1:1 ratios. Such distortion was found, but only in TWC $\delta$. Three regions of the genome were affected and in each case the selection favoured transmission of alleles from ICMP 451

[parent $\mathrm{B}$ in $\mathrm{C} \times(\mathrm{A} \times \mathrm{B})$ ]. There is no evidence, however, that selection is for coupling linkages. The distortion in linkage group 1 was most severe at the top of the group and waned for markers progressively farther down the chromosome (Fig. 3 a) This suggests that the effect is caused by a single gene or gene cluster. Certainly recombination values in TWC 8 are not decreased in that region. The other two linkage groups affected. 4 and 7 (Fig. 3 b.c). are too short to distinguish the alternatives of selection at multiple loci from selection at a single locus associated with linkage drag. The net effects of these disturbances in segregation in the male population would not argue against the findings from the TWC $\delta / T W C$ $\$$ comparisons. Indeed they would, if anything. result in an underestimate of recombination in the TWC $\delta$.

Interestingly. two out of three regions of the genome identified in this study as sources of distorted segregation corresponded with those observed by Liu et al. (1994) in a different mapping population (LGD-I-B-10 $\times$ ICMP 85410). However, it cannot be determined whether the distortions on linkage groups 4 and 7 observed by Liu et al. (1994) were due to selection of alleles transmitted through the male. since these experiments employed a $F_{2}$ population produced by selfing.

The occurrence of disturbed segregation ratios in specific regions of the genome in two independent crosses warrants further study to determine the most likely among several possible available explanations. Gametophytic competition has been observed for several characters in this crop (Sarr and Pernes 1988; Sarr et al. 1988; Robert et al. 1989. 1991), but sporophytic selection could also have contributed to the distortions observed in the population mapped by Liu et al. (1994).

Should gametophytic selection be found to be a widespread and common phenomenon in pearl millet, knowledge of the mechanism involved will facilitate its possible application. Breeders may be able to exploit the genes responsible for gametic selection once genotypes of pearl millet at these loci are known. This information can be obtained by assaying inbred lines for genotype at selected RFLP loci, but will be more costly to obtain for populations under recurrent selection, where large numbers of plants will have to be assayed with very tightly linked markers to obtain reliable estimates of allelic frequencies. Options available, once performance of a genotype can be predicted, range from being able to maximise transmission (e.g., in the return to a recurrent parent genotype), or to preferentially exclude deleterious alleles known to be carried in these regions of the genome.

\section{Conclusions}

A major significance of these results is that there is likely to be little difference in recombination rates recovered from either male or female gametes for the pearl millet breeder to exploit. Of course this conclusion has been obtained from a comparison of only two three-way crosses. However, since the mapping results are similar to those 
found possible in an independent $F_{2}$ population. there is no reason to believe that they are in any way exceptional. These equivalent recombination rates suggest that backcrossing programmes can be carried out in the most convenient manner, rather than using the $F_{1}$ as female as would be suggested from the tomato results ( $\mathrm{De}$ Vicente and Tanksley 1991). However, breeders wishing to avoid surprises due to segregation distortion should use the segregating genome as the female in crosses. Other applications, such as the construction of inbred substitution lines by markerassisted sclection for entire linkage groups of a donor inbred, will not be able to take advantage of reduced recombination in one gamete or the other to hold linkage groups together. Fortunately, given the low rates of recombination observed in $P$.glaucum, such aides are probably not necessary.

Our results indicate that segregation will be more predictable among female gametes than among male gametes in pearl millet. If breeders are seeking Mendelian segregation ratios in this species, they should examine test-cross progenies where the $F_{1}$ has been used as the female parent (contrary to standard practice where it is more often used as the male parent), rather than $F_{2}$ populations, or testcrosses where the $F_{1}$ is used as the pollen parent. This has recently been demonstrated to hold irue where segregation distortion due to gametophytic selection was found in progenies that are predicted to segregate $3: 1$ or $1: 1$ for the yellow seedling character of ICMB 8800)4 (K. N. Rai, personal communication). Further, in a backcrossing program to introduce one or more genes of interest into an elite background, pearl millet breeders should use the recurrent parent as the male, which can conveniently be done by using stored pollen (Hanna 1990) if this facility is available. The male recurrent parent will permit the use of standard formulae (e.g., Sedcole 1977) to calculate the number of plants required to ensure transmission of the donor gene(s) of interest each generation, facilitating their timely and efficient backcross transfer.

Acknowledgements This work was supported by the Overseas Development Administration Plant Sciences Research Programme. We are also grateful to Dr. J. K. M. Brown at the John Innes Centre for the assistance in data analysis and Miss T. Pittaway for her technical assistance. Finally, a special thanks to collaborators in ICRISAT: Mr. M. N. V. Ratnaji Rao, Mr. Mohd. Yousuf and Mr. A.C. Reddy.

\section{References}

Baker BS, Carpenter ATC, Esposito MS, Esposito RE, Sandler L (1976) The genetic control of meiosis. Annu Rev Genet 10:53-134
De Vicente MC. Tanksley SD (1991) Genome-wide reduction in recombination of hackeross progeny derived from male versus female gametes in an interspecific cross of tomato. Theor Appl Genet 8.3:173-178

Devos KM. Millan T. Gale MD (199.3) Comparative RFL.P maps of the homoeologous group-2 chromosomes of wheal, rye and harley. Theor Appl Genet 85:78+3-792

Donis-Keller H. Green P. Helms C. Cartinhour S. Weiffenhach B, Stephens K. Keith TP. Bowden DW. Smith DR. Lander F.S. Botstein D. Akots G. Rediker KS. Gravious T. Brown V. Rising MB. Parker C. Powers JA. Walt DE Kauffinan ER. Bricker A. Phipps P. Muller-Ahle H. Fulton TM. $\mathrm{Ng}_{\mathrm{g}}$ S. Schumm JW. Braman JC. Knowlton RCi. Barker DF, Crooks SM, Lincoln SF. Daly MJ. Abrahamson J (1987) A genetic linkage group map of human genome. Cell 51:319-3.37

Hanna WW (1990) Long-term storage of Pe'nnisetum glancum (L..) R. Br. pollen. Theor Appl Gene1 79:6(1)5-6()8

Heun M. Kennedy AL: Anderson JA. Lapitan NI.V. Sorrells ME. Tanksley SD (199|) Construction of a restriction fragument length polymorphism map for harley (Hordenum inglgare). Genome $34: 4.37-447$

Kleinhof's A, Kilian A. Saghai Maroof MA. Biyashev RM, Hayes P. Chen I:Q. Lapitan N. Fenwick A. Blake TK. Kanazin V. Ananiev E. Dahleen I. Kudrna D. Bollinger J, Knapp SJ, Liu B. Surrells M. Heun M. Framckowiak JD. Hoffman D., Skadsen R. Steffenson BJ (1993) A molecular, isoryme and morphological map of the barley (Horde'um iwlgare) genome. Theor Appl Genet 86:70.5-712

Lander E. Green P. Ahrahamson J. Barlow A. Daley M. Lincoln S. Newhurg L (1987) MAPMAKLE: an interactive computer package for constructing primary genetic linkage maps of experimental and natural populations. Genomic's 1:174-181

Liu CJ. Witcombe JR. Pillaway TS. Nash M. Busso CS. Ciale MD (1994) An RFLP-based genetic map of pearl millel (Pennise'tum glaucum). Theor Appl Genet 89:481-487

Maeda T (1939) Chiasma studies in the silk worm. Bombyx mori $L$. Jpn J Genet 15:118-127

Reeves RH (1990) Sex, strain, and species differences affect recombination across an evolutionarily conserved segment of mouse chromosome 16. Genomics 8:141-148

Robert T. Sarr A. Pernes J (1989) Sélections sur la phase haploïde chez le Mil |Pennisetum typhoides (Burm.) Stupf et Hubh. |: effet de la température. Genome 32:946-952

Robert T, Lespinasse R. Pernes J Sarr A (1991) Gametophytic competition as influencing gene flow between wild and cultivated forms of pearl millet (Pennisetum typhoides'). Genome 34: 195-2(X)

Robertson DS (1984) Different frequency in the recovery of crossover products from male and female gametes of plants hypoploid for B-A translocations in maize. Genetics 107:117-130

Sarr A. Pernes J (1988) Analyses multivariése de descendances de rétrocroisements et mise en évidence de distorsions de ségrégation de caractères quantitatif's chez le mil |Pennisetum yy: phoides (Burm.) Stapf et Hubb. I. Genome 30:411-422

Sarr A, Sandmeier M, Pernes J (1988) Gametophytic competition in pearl millet, Pennisetum typhoides (Stapf el Hubb.). Genome 30:924-929

Sedcole TR (1977) Number of plants necessary to recover a trait. Crop Sci 17:667-668

Zhuchenko AA Korol AB, Vizir IY, Bocharnikova NI, Zamorzaeva NI (1989) Sex differences in crossover frequency for tomato and thale cress (Arabidopsis thaliana). Sov Genet 24:1104-1110 